\title{
Psychological problems and associated factors at 6 years of age: Differences between sexes
}

\author{
Griselda Esparó ${ }^{1}$, Josepa Canals ${ }^{2}$, Margarita Torrente ${ }^{2}$, and Joan D. Fernández-Ballart ${ }^{1}$. \\ ${ }^{1}$ Preventive Medicine and Public Health, Rovira i Virgili University, Spain \\ ${ }^{2}$ Department of Psychology, Rovira i Virgili University, Spain
}

In a non-clinical group of 130 children ( 65 boys and 65 girls), we evaluated the relationships between psychological problems using the Child Behavior Checklist (CBCL) reported by parents, the Inattention Overactivity With Aggression (IOWA) scale reported by teachers, individual factors (Intellectual quotient [IQ], temperament and heart rate) and environmental factors (stress events, mother's profession and being or not being an only child). We found no differences between the sexes in the prevalence of total psychological problems in the clinical range, but girls had significantly more borderline total problems than boys. Girls tended to have more externalizing problems than boys. In boys, there were more links between individual and environmental factors and psychological problems, especially externalizing problems. A high score in psychological problems assessed by the CBCL affected the school performance of boys and the social performance of girls. For boys, IQ was significantly lower when the score for total behavioral problems was higher, and for girls IQ was significantly lower when the score for externalizing problems was higher. Understanding the different levels of vulnerability of the sexes at different periods of development may help to improve the treatment children in this age group receive.

Keywords: psychological problems, sex differences, $C B C L, I Q$

Hemos evaluado, en un grupo de 130 niños (65 niños y 65 niñas) de 6 años de edad, las relaciones que se establecen entre problemas psicológicos $(\mathrm{CBCL}$, obtenido de los padres y IOWA, obtenido de los maestros), factores individuales (cociente intelectual [C.I.], temperamento y frecuencia cardiaca) y factores ambientales (sucesos vitales, profesión materna y tener o no tener hermanos). No se han hallado diferencias entre sexos en la prevalecía de problemas totales de tipo clínico, pero las niñas han presentado significativamente más problemas en el rango límite que los niños. Se ha observado una tendencia a presentar más problemas exteriorizados en las niñas. En los varones se ha encontrado un mayor número de asociaciones entre los factores individuales y ambientales y los problemas psicológicos, principalmente los de tipo exteriorizado. Los problemas psicológicos han afectado la competencia escolar en los niños y la competencia social en las niñas. El C.I. se ha encontrado significativamente más bajo en la puntuación de problemas totales en niños y en la puntuación de problemas exteriorizados en niñas. La comprensión de diferentes vulnerabilidades entre sexos, en los diversos periodos evolutivos, puede ayudar a una mejor intervención en los niños de este grupo de edad.

Palabras clave: problemas psicológicos, diferencias entre sexos, CBCL, C.I.

Correspondence concerning this article should be addressed to Griselda Esparó-Hidalgo, Unidad de Medicina Preventiva y Salud Publica, Facultad de Ciencias de la Salud y Medicina, Universidad Rovira I Virgili, Sant Llorenç 21, E43201 Reus, Cataluña (Spain). E-mail: geh@fmcs.urv.es 
Explaining psychopathology in children and studying the factors behind it, are complex and difficult tasks because biological, individual and environmental factors are all involved in its development.

Sex and age are associated with many differences in psychopathology. Psychopathological disorders are generally more prevalent in boys before puberty (Bilenberg, 1999). After adolescence there is a higher prevalence among girls, particularly in regards to internalizing ${ }^{1}$ problems (Canals, Martí-Hennenberg, Fernández-Ballart, \& Domènech, 1995; Crijnen, Achenbach, \& Verhulst, 1999; Steinhausen, WinklerMetzke, Meier, \& Kannenberg, 1998). Several studies have shown that externalizing ${ }^{2}$ disorders are more common in boys than in girls (Bilenberg, 1999; Bilenberg \& Horder, 1998; Crijnen et al., 1999; Steinhausen et al., 1998), though it appears that this difference becomes evident after 6 years of age (Keenan \& Shaw, 1997).

These differences between sexes suggest that several factors and processes interact throughout the development of psychopathology in a way that is characteristic of each sex, so that boys and girls may display different levels of resistance and vulnerability to different types of psychological problems. A follow-up study by Lewis, Yager, CobhamPortorreal, Klein, Showalker, and Anthony (1991) revealed that early bio-psychosocial variables, which were predictive in males, were not associated with female delinquency. According to some authors (Canals, Fernández-Ballart, \& Esparó, 2002; Davis \& Emory, 1995), behavioral differences and different ways of reacting to stress become apparent before birth, probably due to the effects of prenatal hormonal factors on the brain tissue. These behavioral differences according to sex are also observed in other transitional periods and at times of hormonal changes such as puberty. Walker (2002) reported that in adolescence, changes in brain structure and function determine how gonadal and stress hormones affect the expression of genes, which increases the risk for psychopathology. Also, other studies (Jacobson, Prescott, \& Kendler, 2002; Langbehn, Cadoret, Yates, Troughton, \& Stewart, 1998) have shown that age and sex condition how genetic and environmental factors influence the presence of psychopathology. They have also shown that the influence of genetic factors is greater in girls, and that the influence of environmental factors is greater in boys (Jacobson et al., 2002; Rutter, Giller, \& Hagell, 1998).

However, biological factors do not have the same effect on each subject because, as well as environmental factors, other individual factors and experiences contribute to the development of psychological problems. Of the individual factors, temperament is associated with psychopathology. Colder, Mott, and Berman (2002) supported the existence of interactive models of temperamental risk and, with regard to sex, considered specific patterns of internalizing and externalizing problems. A difficult temperament, basically characterized by negative mood, poor adaptation and excessive activity (Lerner \& Vicary, 1984) is considered to be a predictor of behavioral problems (Sanson, Oberklaid, Pedlow, \& Prior, 1991). In the long term, externalizing problems are more often associated with a difficult temperament, but in children of pre-school age, this relationship is found with both externalizing and internalizing problems (Tschann, Kaiser, Chesney, Alkon, \& Boyce, 1996). Inhibited temperament, or behavioral inhibition, characterized by shyness towards unknown stimuli (Kagan, Reznick, \& Snidman, 1998; Prior, Smart, Sanson, \& Oberklaid, 2000) has also been considered to be a predictor of anxiety problems (Prior et al., 2000; Schwartz, Snidman, \& Kagan, 1999). This is observed more frequently in girls than in boys (Schwartz et al., 1999).

Like temperament, heart rate (HR) is another individual physiological factor that is determined from the prenatal period and present at birth. Heart rate reflects the activity of the sympathetic and parasympathetic ANS and may predispose a child to psychopathology. A low HR is associated with externalizing psychopathology (Raine, 1993; Raine, Venables, \& Mednik, 1997), and more so in boys than in girls (Calkins \& Dedmon, 2000). A high HR, on the other hand, is associated with internalizing psychopathology in pre-school children (Zahn-Waxler, Cole, Welsh, \& Fox, 1995), children and adolescents (Raine et al., 1997).

Another individual factor related to the presence of psychopathology is intelligence quotient (IQ) (Campbell, 1994; Dietz, Lavigne, Arend, \& Rosenbaum, 1997). A low IQ has been associated with psychopathology in normal samples of pre-school children (Dietz et al., 1997; Pianta \& Caldwell, 1990; Pianta \& Castaldi, 1989), in children of school age (Anderson, Williams, McGee, \& Silva, 1989; Howlin \& Rutter, 1987) and in adolescents (Goodman, Simonoff, \& Stevenson, 1995), and it appears that this relationship is stable over time (Anderson et al., 1989). Epidemiological studies have found links between low intellectual capacity and certain psychological problems, such as hyperactivity (McGee, Partridge, Williams, \& Silva, 1991) and delinquency (White, Moffitt, \& Silva, 1989). However, others have observed that this relationship exists for psychopathology in general (Pianta \& Caldwell, 1990; Pianta \& Castaldi, 1989). Environmental factors are also associated with the presence of psychopathology. Many acute and chronic environmental factors interact with the aforementioned factors, and others, throughout the child's development. Children who are subject to stressful situations or are from a low socioeconomic level are found to have

\footnotetext{
1 Psychological problems of anxiety and depression based on the dimensional classification of psychopathology (Achenbach, 1991).

2 Psychological problems of aggression and delinquent behavior based on the dimensional classification of psychopathology (Achenbach, 1991).
} 
more behavioral or emotional problems (Bilenberg, 1999; Larsson \& Frisk, 1999; Rutter, 1987).

We have seen how sex and age can condition how other factors interact with the development of psychopathology. Few studies have been carried out in preschoolers, however, and we do not know the effects of these interactions at this age. We have therefore evaluated a sample of boys and girls at the end of the preschool stage. In this study we considered the age of 6 as a time of transition in the development of the child. Our main aims were to analyze the influence of several individual and environmental factors on the presence of behavioral and emotional problems, and to study the differences between sexes.

\section{Method}

\section{Participants}

Our group was comprised of 130 children (65 boys and 65 girls). The average age of the children was 5.8 years ( $S D$ $=0.41$ ). Eighty-five children (44 boys and 41 girls) were from a longitudinal study in which their parents had volunteered to take part. Forty-five children ( 21 boys and 24 girls), whose parents gave their informed consent for them to take part, were from a state school. All families were from the Mediterranean cities of Reus or Tarragona in Catalonia (Spain). These cities are situated very close to each other and have 91,000 and 112,000 inhabitants, respectively. The socioeconomic level in these cities is average or above average in relation to the general socioeconomic level in Spain.

\section{Instruments}

Child Behavior Checklist (CBCL; Achenbach, 1991). This is a parental measurement of a child's skills as well as their emotional and behavioral problems. It has been translated into Catalan for the purpose of this study.

Skills are divided into social skills, academic skills, activities, and total skills. Psychological problems, rated by the children's parents, are measured by 118 items. Items are divided into nine groups of syndromes or scales. These are: withdrawn, somatic complaints, anxious/depressed, social problems, thought problems, attention problems, delinquent behavior, aggressive behavior, and sex problems. Withdrawn, somatic complaints and anxious/ depressed syndromes comprise the internalizing dimension while delinquent behavior and aggressive behavior comprise the externalizing dimension. In all analyses performed in this study, we used the T-score of each of the dimensions and scales. On the basis of the child's T-score, he or she was classified into one of the following groups, according to severity: normality, borderline or clinical.

Dimensions of Temperament Survey-Revised (DOTS-R; Windle \& Lerner, 1986). This is a 54-item questionnaire designed to assess temperamental characteristics in children. Each item has 4 possible answers to choose from: generally false, more false than true, more true than false, generally true. The items are divided into 9 separate factors. These are: General Activity, Sleep Activity, ApproximationWithdrawal, Flexibility-Strictness, Mood, Sleeping Rhythmicity, Eating Habits, General Habits and PersistenceAttention. For this study, we did not consider the eating habits or general habits dimensions because we considered them to be more strongly influenced by learning strategies. We used a version of the survey that was specially translated into Catalan for this experiment. Internal consistency in the various dimensions was moderate to high (between .60 and .90). This internal consistency is similar to that obtained by Windle and Lerner (1986) (between .61 and .95). InattentionOveractivity with Aggression (IOWA) Conners' Teachers' Rating Scale (Loney \& Milich, 1982). The IOWA includes an aggression scale and a hyperactivity scale with 5 items each, which the teacher uses to evaluate the child on the basis of 4 possible answers: not at all, just a little, pretty much and very much. We used a version of the IOWA scale that was specially translated into Catalan for our research. Internal consistency in the two dimensions was high (.84 in aggression and .80 in hyperactivity). This internal consistency is similar to that obtained by Loney and Milich (1982) $(.85$ in aggression and .87 in hyperactivity).

Wechsler Preschool and Primary Scale of Intelligence (WPPSI; Wechsler, 1996). This is an individually administered IQ test. It is a downward extension of the WISC that contains 5 verbal and 5 performance subtests. We obtained three measurements of IQ: total, verbal and performance. The WPPSI was administered to the children in their mother tongue: Children who generally spoke Castilian Spanish were administered the test as it appears in its original version, and children who generally spoke Catalan were given simultaneously translated instructions. Catalonia is a bilingual region in which both of these languages are spoken and understood perfectly.

Heart rate. The children's heart rates were measured using a WS-330 digital sphygmomanometer (Nissei SA, Japan CE 0123) fitted to their left wrists.

Sociodemographic factors were reported by parents in the CBCL. The parents' professional levels were divided into 5 groups: unemployed, unskilled, skilled, middle and upper management, and business. The parents were also asked whether their children had, in the previous few months, experienced any vital event that could have caused them stress (e.g. the death of a family member, separation of their parents, illness, change of address, or any other event they considered relevant).

\section{Procedure}

The parents of the 85 children who took part in the longitudinal study were contacted by telephone after 5 years 
of non-study. Once they had agreed to take part in the study, an evening was arranged for the WPPSI study to be carried out, on University premises, and they were sent the CBCL and the DOTS by post. These questionnaires could be completed by either the child's mother or father. They were also sent the IOWA questionnaire, which they had to give to the child's teacher to complete.

The parents of the 45 children who participated from the school were informed of the study in a letter sent by the school. Once they had agreed to take part, they were asked to complete the DOTS and the CBCL, and the children's teachers completed the IOWA for each of their pupils who took part in the study. Every evening the examiner went to the school to evaluate one of the children and complete the WPPSI and HR.

Two of the 130 children who took part did not hand in the CBCL and DOTS questionnaires. Two children did not hand in the IOWA scale. It was not possible to do the WPPSI test for one child. It was not possible to measure the heart rate of two of the children.

\section{Data Analysis}

To estimate the effect of individual and environmental factors on behavioral and emotional problems, we fitted separate multiple linear regression models for the individual and environmental factors. This model can be adjusted for other variables that could interfere with the relationship of interest. To compare a child's abilities over three ranges of severity of psychological problems, we used ANOVAs and multiple comparison corrections when necessary. To compare a child's intelligence quotient over two ranges of severity of psychological problems, we used the student's T-test.

We rejected the null hypothesis when $p<.05$. Version 10.0 for Windows of the Statistical Package for Social Sciences (SPSS) was used for exploratory and inferential analysis.

\section{Results}

\section{Sex Differences}

The T-score for total behavior problems was higher for girls than for boys (see Table 1). The distribution of range was significantly different between the sexes $(p<.05)$. Boys were more often within the normal range than girls. The Tscore for externalizing problems was significantly higher $(p$ $<.05)$ for girls than for boys. Girls were within the clinical or borderline range more often than boys. There were no significant differences between the sexes in any of the nine CBCL scales.

Regarding the IOWA scale, the score for hyperactivity was higher for boys and the score for aggression was higher for girls, but the differences were not statistically significant.
There were no significant differences between boys and girls in the dimensions of temperament (DOTS).

The average scores for IQ were not significantly different between the sexes, although the girls' scores for verbal IQ $(116 ; S D=12.57)$ were slightly higher than those for boys (114.5; $S D=12.44)$. There were hardly any differences in the scores for total IQ between the sexes (boys: 113.25; SD = 14.28; girls: 113.69; $S D=12.67)$. This was also true for the scores for performance IQ (boys: 108.42; $S D=14.76$; girls: $107.74 ; S D=12.76$ ).

There were no significant differences between the sexes in the scores for heart rate.

\section{Effect of Individual and Environmental Factors on Psychological Problems in Boys and Girls}

We first studied, in the entire group, how sex, as an independent variable, interacts with the other variables in the models. Our results showed that there were significant interactions between sex and the other variables. We therefore considered that there were real differences between the sexes and analyzed the boys and girls separately.

To show how the individual and environmental variables were related to psychological problems, multiple linear regressions of individual factors (including temperament, HR and IQ) and environmental factors (including mother's profession, stressful events and being or not being an only child) were performed for both sexes.

For boys, the model of individual factors (Table 2) significantly explains the CBCL T-score for total behavior problems, externalizing problems, delinquent behavior, aggressive behavior, internalizing behavior, anxious-depressed and attention problems. The model also significantly explains the IOWA scores for hyperactivity and aggression. Variances ranged between $17 \%$ and $44.5 \%$. Specifically, the temperament dimension of general activity was significantly and positively related to all the behavioral problems mentioned except internalizing behavior and anxious-depressed syndromes. A higher approximation was significantly and positively related to externalizing problems. Also, a low level of flexibility was significantly related to total behavior problems and externalizing problems. Mood was significantly and negatively related only to anxious-depressed syndromes. Sleep rhythmicity was significantly and negatively related to total behavior problems, externalizing problems and delinquent behavior problems.

Verbal IQ was only negatively and significantly related to attention problems. Performance IQ was positively and significantly related to internalizing problems.

Heart rate was negatively and significantly related to externalizing problems.

For girls, the model only showed significant relationships between the CBCL T-score for attention problems and internalizing behavior, with variances of $50.2 \%$ and $17.3 \%$, respectively. Attention problems were positively and significantly related to general activity as indicated by their 
Table 1

Means, Standard Deviations (in parenthesis), and Distribution of the CBCL and IOWA Scales According to Range

\begin{tabular}{|c|c|c|}
\hline & Boys $n=65$ & Girls $n=65$ \\
\hline \multicolumn{3}{|l|}{ CBCL } \\
\hline \multicolumn{3}{|c|}{ Total behavior problems } \\
\hline$M(S D)$ & $53.38(9.57)$ & $55.05(9.03)$ \\
\hline \multicolumn{3}{|l|}{ Distribution: $(\%)^{*}$} \\
\hline Normality & 78.1 & 64.0 \\
\hline Borderline & 4.7 & 18.8 \\
\hline Clinical level & 17.2 & 17.2 \\
\hline \multicolumn{3}{|c|}{ Internalizing problems } \\
\hline$M(S D)$ & $54.00(9.71)$ & $54.22(8.58)$ \\
\hline \multicolumn{3}{|l|}{ Distribution: (\%) } \\
\hline Normality & 67.2 & 73.4 \\
\hline Borderline & 20.3 & 12.5 \\
\hline Clinical level & 12.5 & 14.1 \\
\hline \multicolumn{3}{|c|}{ Externalizing problems } \\
\hline$M(S D)^{*}$ & $52.00(9.34)$ & $55.75(8.69)$ \\
\hline \multicolumn{3}{|l|}{ Distribution: (\%) } \\
\hline Normality & 79.7 & 71.8 \\
\hline Borderline & 4.7 & 6.3 \\
\hline Clinical level & 15.6 & 21.9 \\
\hline \multicolumn{3}{|l|}{ IOWA } \\
\hline \multicolumn{3}{|l|}{ Hyperactivity } \\
\hline \multicolumn{3}{|l|}{$M(S D)$} \\
\hline Distribution: (\%) & $4.48(3.29)$ & $3.44(3.36)$ \\
\hline Normality & 95.3 & 96.9 \\
\hline Risk & 4.7 & 3.1 \\
\hline \multicolumn{3}{|l|}{ Aggression } \\
\hline \multicolumn{3}{|l|}{$M(S D)$} \\
\hline Distribution: (\%) & $1.80(2.21)$ & $2.39(3.16)$ \\
\hline Normality & 95.3 & 90.8 \\
\hline Risk & 4.7 & 9.2 \\
\hline
\end{tabular}

Note. CBCL. Normality: T-scores of 59 or less in the total problems, internalizing problems and externalizing problems dimensions. Borderline: T-scores between 60 and 63 in the total problems, internalizing problems and externalizing problems dimensions. Clinical level: scores of 64 or more in the total problems, internalizing problems and externalizing problems dimensions. IOWA. Normality: scores of less than 11 in hyperactivity and scores of less than 7 in aggression. Risk: scores of 11 or more in hyperactivity and scores of 7 or more in aggression.

$* p<.05$.

regression coefficient $(B=0.64 ; S E=0.15 ; p<0.001)$ and negatively and significantly related to task orientation $(B=$ -0.48; $S E=0.18 ; p=0.012$ ). Internalizing behavior was significantly related to a low level of flexibility.

For boys, the model of environmental factors significantly explains the CBCL scores for aggressive behavior $(p<.05$; $\left.R^{2} .100=28.1\right)$ : stress was the only variable that was significantly and positively related $(B=8.96, S E=2.13 ; p<.001)$. The effect of environmental factors on externalizing problems was almost significant for girls $\left(p=0.061 ; R^{2} \times 100=13.4\right)$ as well as for boys ( $p=0.073 ; R^{2}$ x $100=11.6$ ). Although the model of these factors does not significantly explain the externalizing problems, stress was significantly related to higher scores (for boys: $B=$
9.24; $S E=3.53 ; p=0.012$; for girls: $B=6.32 ; S E=3.11 ; p=$ 0.049). Girls whose mothers have a job in middle or upper management had a higher score for externalizing problems than girls whose mothers do not work. This was not true for boys $(B=10.41 ; S E=5.2 ; p=0.052)$.

\section{Relationship Between Low Competence Scores and Psychological Problems: Differences Between the Sexes}

For boys, we found that when the score for psychological problems was high, the only area of competence that decreased significantly was school competence (Table 3). Specifically, the average score for school competence in the total-behavior 


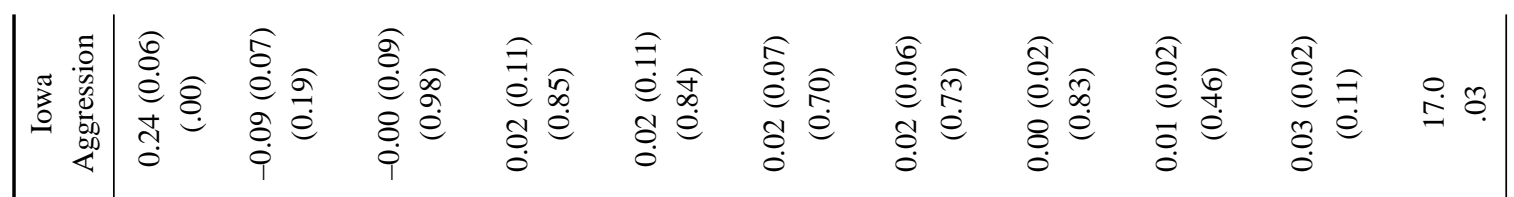

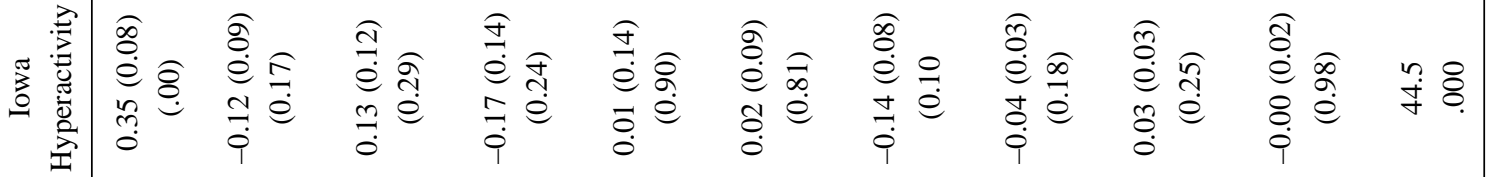

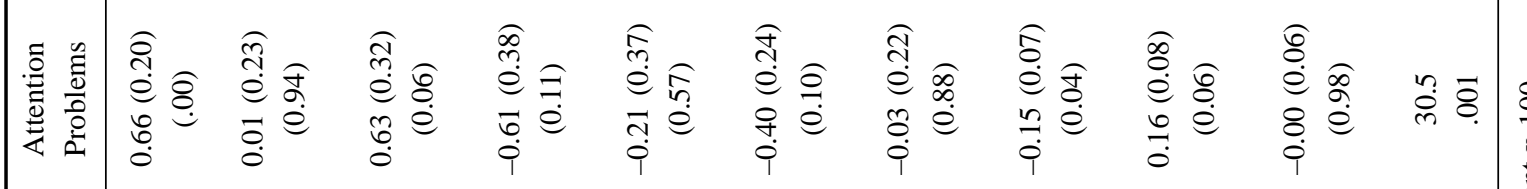

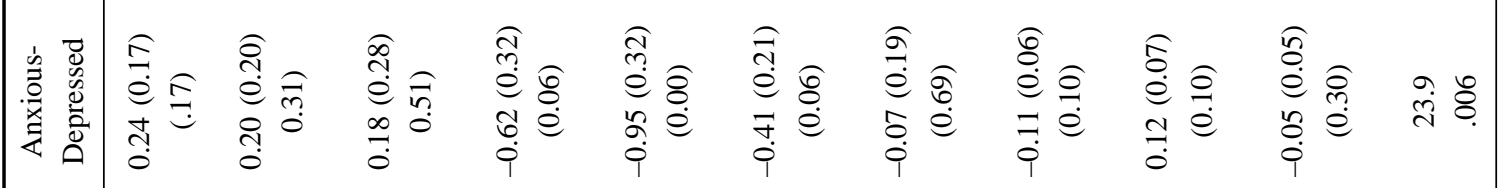

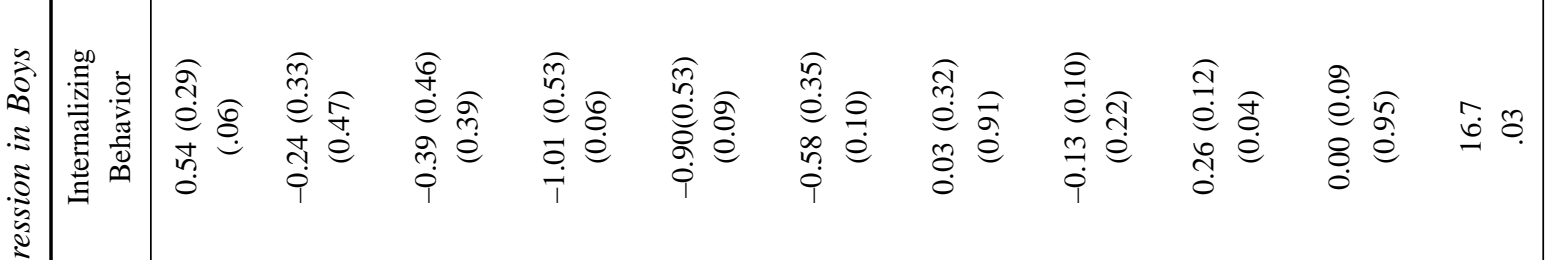

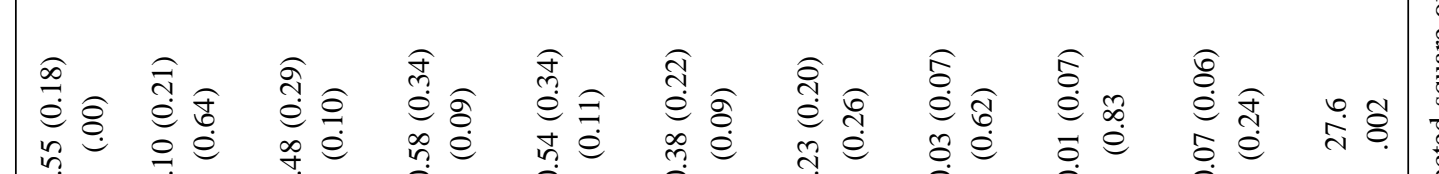

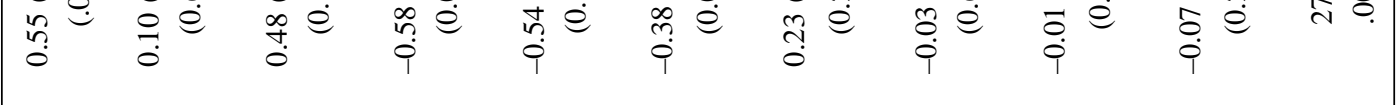

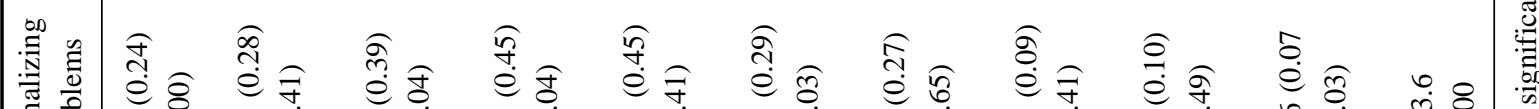

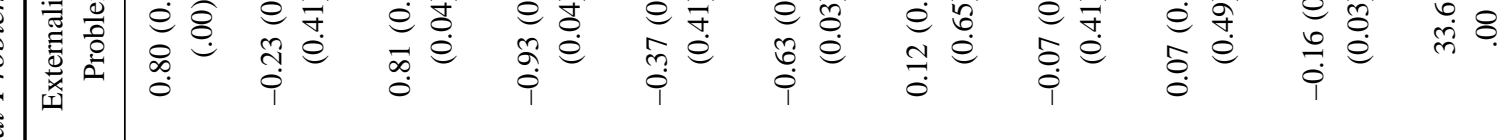
हु

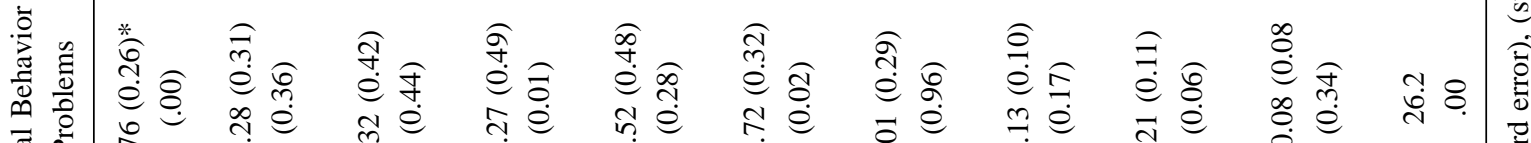

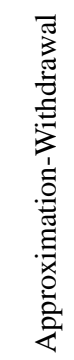

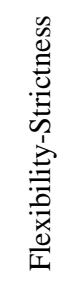

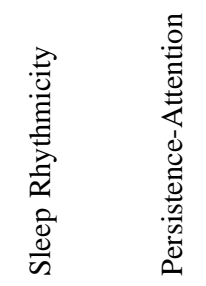

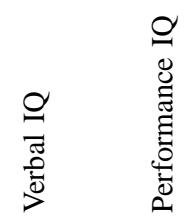
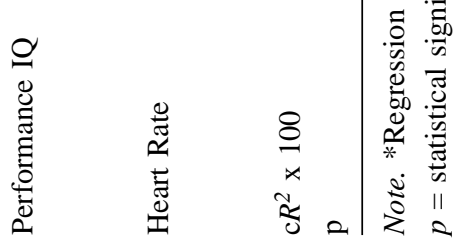
problems and anxious-depressed problems was significantly lower in the borderline range than in the normality range. The average score for school competence in the internalizingbehavior and attention-problems dimensions, on the other hand, was significantly lower in the clinical range than in the normality range.

For girls, we found that only social competence decreased significantly. Specifically, the average score for this area of competence was lower in the clinical range than in the normality range (Table 3). We also found that, in thought problems, the average score for social competence was significantly lower in the borderline range than in the normality range.

\section{Relationship between Intelligence Quotient and Psychopathology: Differences between the Sexes}

To determine the relationship between IQ and psychological problems, we created two groups of severity according to the CBCL and the IOWA: the normality group and the risk group (Table 4). In boys, both total and verbal IQ were significantly lower in the risk group of total behavior problems than in the normal group. In girls, verbal IQ was significantly lower in the risk scores of the IOWA and performance IQ was significantly lower in the group with attention problems.

Table 3

Means and Standard Deviations (in parenthesis) of Competences According to Severity Levels of Psychological Problems: Significant Relationships

\begin{tabular}{|c|c|c|c|c|}
\hline & Normality (a) & Borderline ( $b$ ) & Clinical Level (c) & $\begin{array}{l}\text { Significantly Different } \\
\text { from Normal Group }\end{array}$ \\
\hline \multicolumn{5}{|l|}{ Boys } \\
\hline \multicolumn{5}{|l|}{ School competence in: } \\
\hline Total Behavior Problems & $49.30(6.22)$ & $38.00(10.54)$ & $44.56(9.19)$ & $b^{*}$ \\
\hline Internalizing Problems & $49.36(6.13)$ & $46.82(9.00)$ & $40.83(8.95)$ & $c^{*}$ \\
\hline Anxious-Depressed & 48.64(7.02) & $39.40(9.21)$ & $\longrightarrow$ & $b^{*}$ \\
\hline Attention Problems & $49.13(6.74)$ & $41.80(6.26)$ & $33.00(8.49)$ & $c^{* *}$ \\
\hline \multicolumn{5}{|l|}{ Girls } \\
\hline \multicolumn{5}{|l|}{ Social competence in: } \\
\hline Total Behavior Problems & $41.79(7.67)$ & $42.50(7.60)$ & $34.33(7.58)$ & $c^{*}$ \\
\hline Aggressive Behavior & $41.93(7.47)$ & $33.75(2.50)$ & $25.00(1.41)$ & $c^{* *}$ \\
\hline Thought Problems & $41.02(7.86)$ & $29.50(4.95)$ & $\longrightarrow$ & $\mathrm{b}^{*}$ \\
\hline
\end{tabular}

Note. A post-hoc test cannot be performed because there are less than two individuals in the clinical range.

$* p<.05 . * * p<.01$.

Table 4

Intelligence Quotient (Mean and Standard Deviations) According to Severity Levels of Psychopathology: Significant Relationships*

\begin{tabular}{|c|c|c|}
\hline & Normality (1) & Borderline and Clinical/ Risk (2) \\
\hline \multicolumn{3}{|l|}{ Boys } \\
\hline \multicolumn{3}{|l|}{ Total IQ in: } \\
\hline Total Behavior Problems & $115.14(14.19)$ & $106(12.98)$ \\
\hline \multicolumn{3}{|l|}{ Verbal IQ in: } \\
\hline Total Behavior Problems & $110.04(14.24)$ & $101.21(14.29)$ \\
\hline \multicolumn{3}{|l|}{ Girls } \\
\hline \multicolumn{3}{|l|}{ Total IQ in: } \\
\hline IOWA Hyperactivity & $114.55(12.23)$ & $95.00(12.73)$ \\
\hline \multicolumn{3}{|l|}{ Verbal IQ in: } \\
\hline IOWA Hyperactivity & $108.61(12.31)$ & $88.50(12.02)$ \\
\hline IOWA Aggression & 109.07(12.09) & $97.50(14.88)$ \\
\hline \multicolumn{3}{|l|}{ Performance IQ in: } \\
\hline Attention Problems & $117.17(12.36)$ & $105.60(9.26)$ \\
\hline
\end{tabular}

Note. (1) Range of normality according to CBCL. No risk according to IOWA. (2) Borderline range and clinical range according to CBCL. Risk according to IOWA.

*All differences were statistically significant: $p<.05$. 


\section{Discussion}

In this study we saw that, at 6 years of age, sex is a differential factor in psychopathology. The relationship between the factors we studied and psychopathology is stronger for boys than it is for girls.

The prevalence of clinical problems was the same for boys and girls $(17.2 \%)$ but, unlike the results of other authors (Bilenberg, 1999), it was significantly higher for boys than it was for girls in the normality range. Also, girls had a greater prevalence of externalizing problems in the clinical range than boys, though this difference was not significant. We can therefore infer, like Keenan \& Shaw (1987), that the greater externalizing psychopathology in boys becomes apparent after 6 years of age.

For boys, the individual factors are mainly related to externalizing behavior. In agreement with other authors (Colder, Mott, \& Berman, 2002; Kingston \& Prior, 1995; Giancola, Mezich, \& Tarter, 1998), the temperament characteristics of high general activity and an irregularity in the biological function of sleeping habits are related to externalizing problems. This relationship was also observed by Colder et al. (2002) for internalizing psychopathology. However, our results also showed that there was a link between this type of psychopathology and negative mood. For girls, relationships between temperament and psychopathology were found for non-externalizing psychopathology. The relationship between psychopathology and IQ was different for boys and girls. For boys, the regression model showed that there was an inverse relationship between verbal IQ and attention problems and that, in general, there was a relationship between a lower IQ and psychological problems. For girls, the relationship between IQ and psychological problems was mainly focused on attention problems, hyperactivity and aggression. These results agree with those of Anderson et al. (1989), McGee et al. (1991), and Pianta and Caldwell (1990), although in these studies, the relationship was not different between the sexes. These differences suggest that, for girls, a low IQ is a consequence of this type of psychopathology but, for boys, a low IQ could be a cause of psychopathology. Other authors, however, (Raine, 1993; Raine et al., 1997; Scarpa \& Raine, 1997) found that there is an inverse relationship between heart rate and externalizing problems in boys, which reaffirms the idea that the ANS is a physiological predisposing factor in behavioral disorders. We found no relationship between heart rate and internalizing problems. Nor did we find this vulnerability of the ANS for girls.

The relationship between competence and psychopathology was also different for boys and girls. Boys only had weaknesses in school competence and in relation to nonexternalizing problems. Girls, on the other hand, had weaknesses in social competence and in relation to aggressive behavior and thought problems. This may be because culturally, for girls, a pattern of externalizing behavior would not be accepted and they would be rejected socially.
As with individual factors, stress, as an environmental variable, is associated with aggressive behavior in boys such that the greater the stress, the more aggressive the behavior. These results support those of Rutter (1987), who found that stress was a risk factor in the development of behavioral problems.

From the results of our study, we can conclude that at 6 years of age there are no differences between the sexes regarding the prevalence of total problems in the clinical range, though we found that girls have a greater prevalence of problems at the borderline level. Girls tended to have a greater prevalence of externalizing problems. For boys, psychological problems, particularly externalizing problems, are more related to constitutional factors than they are for girls. We may deduce that girls are more vulnerable to other environmental factors or, as Jacobson et al. (2002) found, to genetic factors. Also, girls are probably more vulnerable to biosocial factors at a later stage of development and this coincides with an increase in internalizing problems after puberty (Bilenberg, 1999; Canals et al, 1995; Crijnen et al., 1999; Schwartz et al., 1999).

This is not a longitudinal study and we are therefore unable to make predictions regarding psychopathology. Further studies with many variables and follow-up studies are needed to define the complex associations between factors and their later consequences. However, the relationships and the differences we have found between the sexes have clinical implications.

\section{References}

Achenbach, T.M. (1991). Manual for the Child Behavior Checklist/ 4-18 and 1991 profile. Burlington, VT: University of Vermont.

Anderson, J., Williams, S., McGee, R., \& Silva, P. (1989). Cognitive and social correlates of DSM-III disorders in preadolescent children. Journal of the American Academy of Child and Adolescent Psychiatry, 28, 842-846.

Bilenberg, N. (1999). The Child Behavior Checklist (CBCL) and related material: Standardization and validation in Danish population based on clinically based samples. Acta Psychiatrica Scandinavica, 100, 2-37 (supplement).

Bilenberg, N., \& Horder, K. (1998). Behavioral symptoms among children and adolescents. Screening with the help of a questionnaire in a group of children aged between 4 and 17 . Ügeskrift für Laeger, 160, 4423-4428.

Calkins, S.D., \& Dedmon, S.E. (2000). Physiological and behavioral regulation in two-year-old children with aggressive/destructive behavior problems. Journal of Abnormal Child Psychology, 28, 103-118.

Campbell, S.B. (1994). Hard-to-manage preschool boys: Externalizing behavior, social competence, and family context at 2-year follow-up. Journal of Abnormal Child Psychology, $22,147-166$. 
Canals, J., Fernández-Ballart, J., \& Esparó, G. (2003) Evolution of neonatal behavior assessment scale scores in the first month of life. Infant Behavior and Development, 26, 227-237.

Canals, J., Martí-Henneberg, C., Fernández-Ballart, J., \& Domènech, E.(1995). A longitudinal study of depression in an urban Spanish pubertal population. European Child \& Adolescent Psychiatry, 4, 102-111.

Colder, C.R., Mott, J.A., \& Berman, A.S. (2002). The interactive effects of infant activity level and fear on growth trajectories of early childhood behavior problems. Development and Psychopathology, 14, 1-23.

Crijnen, A.A.M., Achenbach, T.M., \& Verhulst, F.C. (1999). Problems reported by parents of children in multiple cultures: The Child Behavior Checklist syndrome constructs. American Journal of Psychiatry, 156, 569-574.

Davis, M., \& Emory, E. (1995) Sex differences in neonatal stress reactivity. Child Development, 66,14-27.

Dietz, K.R., Lavigne, J.V., Arend, R., \& Rosenbaum, D. (1997). Relation between intelligence and psychopathology among preschoolers. Journal of Clinical Child Psychology, 26, 99-107.

Giancola, P., Mezzich, A., \& Tarter, R. (1998). Executive cognitive functioning, temperament, and antisocial behavior in conduct disordered adolescent females. Journal of Abnormal Pyschology, 107, 629-641.

Goodman, R., Simonoff, E., \& Stevenson, J. (1995). The relationship of child IQ, parental IQ and sibling IQ to child behavioural deviance scores. Journal of Child Psychology and Psychiatry, 36, 409-425.

Howlin, P., \& Rutter, M. (1987). The consequences of language delay for other aspects of development. In W. Yule \& M. Rutter (Eds.), Language development and disorders (pp. 271-294). London: MacKeith.

Jacobson, K.C., Prescott, C.A., \& Kendler, K.S. (2002). Sex differences in the genetic and environmental influences on the development of antisocial behavior. Development and Psychopathology, 14, 395-416.

Kagan, J., Reznick, J.S., \& Snidman, N. (1998). Biological bases of childhood shyness. Science, 240, 167-173.

Keenan, K., \& Shaw, D. (1997). Developmental and social influences on young girls' early problem behavior. Psychology Bulletin, 121, 95-113.

Kingston, L., \& Prior, M. (1995). The development of patterns of stable, transient, and school-age onset aggressive behavior in young children. Journal of the American Academy of Child and Adolescent Psychiatry, 34, 348-358.

Langbehn, D.R., Cadoret, R.J., Yates, W.R., Troughton, E.P., \& Stewart, M.A (1998). Distinct contributions of conduct and oppositional defiant symptoms to adult antisocial behavior: Evidence from an adoption study. Archives of General Psychiatry, 55, 821-829.

Larsson, B., \& Frisk, M. (1999). Social competence and emotional/ behaviour problems in 6-16-year-old Swedish schoolchildren. European Child and Adolescent Psychiatry, 8, 24-33.

Lerner, J.V., \& Vicary, J.R. (1984). Difficult temperament and drug use. Journal of Drug Education, 14, 1-8.
Lewis, D., Yager, C., Cobham-Portorreal, C., Klein, N., Showalker, C., \& Anthony, A. (1991). A follow-up from the female delinquents: maternal contributions to the perpetuation of deviance. Journal of the American Academy of Child and Adolescent Psychiatry, 30, 197-201.

Loney, J., \& Milich, R. (1982). Hyperactivity, inattention and aggression in clinical practice. Advances in Developmental and Behavioral Pediatrics, 3, 113-147.

McGee, R., Partridge, F., Williams, S., \& Silva, P.A. (1991). Twelve-year follow-up of preschool hyperactive children. Journal American Academy of Child and Adolescent Psychiatry, 30, 224-232 .

Pianta, R.C., \& Caldwell, C.B. (1990). Stability of externalizing symptoms from kindergarten to first grade and factors related to instability. Development and Psychopathology, 2, 247-258.

Pianta, R.C., \& Castaldi, J.(1989). Stability of internalizing symptoms from kindergarten to first grade and factors related to instability. Development and Psychopathology, 1, 305-316.

Prior M., Smart, D., Sanson, A., \& Oberklaid, F. (2000). Does shyinhibited temperament in childhood lead to anxiety problems in adolescence? Journal American Academy of Child and Adolescent Psychiatry, 39, 461-468 .

Raine, A. (1993). The psychopathology of crime: criminal behavior as a clinical disorder. San Diego, CA: Academic Press.

Raine, A., Venables, P.H., \& Mednick, S.A. (1997). Low Resting Heart Rate at Age 3 Years Predisposes to Aggression at age 11 years: Evidence from the Mauritius Child Health Project. Journal of the American Academy of Child and Adolescent Psychiatry, 36, 1457-1464.

Rutter, M. (1987). Psychosocial resilience and protective mechanisms. American Journal of Orthopsychiatry, 57, 316331.

Rutter, M., Giller, H., \& Hagell, A. (1998). Antisocial behavior by young people. Cambridge, UK: Cambridge University Press.

Sanson, A., Oberklaid, F., Pedlow, R., \& Prior, M. (1991). Risk indicators: Assessment of infancy predictors of pre-school behavioural maladjustment. Journal of Child Psychology and Psychiatry, 32, 609-626.

Scarpa, A., \& Raine, A. (1997). Psychophysiology of anger and violent behavior. The Psychiatric Clinics of North America, 20, 375-394.

Schwartz, C.E., Snidman, N., \& Kagan, J. (1999). Adolescent social anxiety as an outcome of inhibited temperament in childhood. Journal American Academy of Child and Adolescent Psychiatry, 38, 1008-1015.

Steinhausen, H.C., Winkler-Metzke, C., Meier, M., \& Kannenberg, R. (1998). Prevalence of child and adolescent psychiatric disorders: The Zürich epidemiological study. Acta Psychiatrica Scandinavica, 98, 262-271.

Tschann, J.M., Kaiser, P., Chesney, M.A., Alkon, A., \& Boyce, T. (1996). Resilience and vulnerability among preschool children: Family functioning, temperament, and behavioral problems. Journal American Academy of Child and Adolescent Psychiatry, $35,184-192$. 
Walker, E.F. (2002). Adolescent neurodevelopment and psychopathology. Current Directions in Psychological Science, 11, 24-28.

Wechsler, D. (1996). WPPSI, Escala de Inteligencia de Weschler para preescolar y primaria. Manual adaptación española. Madrid: TEA.

White, J.L., Moffitt, T.E., \& Silva, P.A (1989). A prospective replication of the protective effects of IQ in subjects at high risk for juvenile delinquency. Journal of Consulting and Clinical Psychology, 57, 719-724.

Windle, M., \& Lerner, R.M. (1986). Reassessing the dimensions of temperament individuality across the life span: The revised dimensions of temperament survey (DOTS-R). Journal of Adolescent Research, 1, 213-230.

Zahn-Waxler, C., Cole, P.M., Welsh, J.D., \& Fox, N.A. (1995). Psychophysiological correlates of empathy and prosocial behaviors in preschool children with behavior problems. Development and Psychopathology, 7, 27-48.

Received May 14, 2003 Revision received March 15, 2004 Accepted March 26, 2004 